
\title{
is Research Suare \\ Reefscapes of fear assess tradeoffs of risk and reward on coral reefs
}

\section{Margaret A. Malone ( $\square$ mmalon29@uic.edu )}

University of Illinois at Chicago https://orcid.org/0000-0001-8853-7096

\section{Gregorio de Chevalier}

Universiteit van Amsterdam

\section{Christopher J. Whelan}

University of Illinois at Chicago

Joel S. Brown

University of Illinois at Chicago

\section{Research Article}

Keywords: Ecology of fear, predation risk, foraging, behavior, landscape of fear, tradeoffs

Posted Date: November 29th, 2021

DOI: https://doi.org/10.21203/rs.3.rs-1056327/v1

License: (9) This work is licensed under a Creative Commons Attribution 4.0 International License. Read Full License 


\section{Abstract}

Degradation of coral reef habitats changes the abundance and community composition of fishes due in part to changes in the ecology of fear. The ecology of fear sees the predator-prey system as a dynamic game of behavioral responses to perceived risk with population and community level consequences. We measure spatial variation in predation risk as landscapes of fear. We consider changes in predation risk with habitat quality and examine the effects of fear on coral reefs in Kāne'ohe Bay, O'ahu, Hawai'i. First, we associate fish and benthic communities on patch reefs with varying degradation due to invasive algae (Euchema spp. and Kappaphycus spp.). Next, we quantify the spatio-temporal variation of risk (reefscape of fear) of a common Hawaiian fish (saddle wrasse, hīnālea lau wili, Thalassoma duperrey) across reefs of varying degradation. Finally, we assess the tradeoffs in resource availability and predation risk on these reefs. At the scale of whole reefs, saddle wrasse responded to perceived risk. Intensity of patch use (measured by giving-up densities) by wrasse indicated risky reefs. Such reefs differed in benthic and fish community composition. We demonstrated the impact of an altered reefscape of fear due to habitat degradation. Habitat degradation seems to influence the tradeoff between resource availability and safety. From wrasse abundances and their patch use behavior we can classify the reefs into categories based on risk and resource availability. Allowing fish to reveal their perceptions of habitat qualities through their behaviors provides critical information for assessing and monitoring reefs.

\section{Introduction}

Habitat degradation is a major cause of biodiversity loss worldwide (Dudgeon et al. 2006; Baker et al. 2008; Newbold et al. 2015). Specifically, coral reef habitats face critical declines from multiple sources of degradation including coral bleaching, invasive species, intense hurricanes, and destructive fishing (Pratchett et al. 2014). Degradation of coral reef habitats reduces coral cover and structure (Feary et al. 2007; Graham and Nash 2013), which ultimately changes fish abundance and community composition of fishes (Wilson et al. 2008; Pratchett et al. 2011; Graham et al. 2015). Fishes on reefs lacking structural complexity may experience higher predation rates due to decreased refuge availability (Almany 2004; Coker et al. 2009). While habitat degradation increases the lethal effects of predators on coral reefs, we are just beginning to understand how habitat degradation alters their non-lethal effects. These non-lethal or non-consumptive effects (NCEs) of predation may influence the morphology, physiology, or behavior of fishes living on coral reefs (Mitchell and Harborne 2020). Furthermore, habitat degradation may influence the tradeoffs between resource availability and predation risk on coral reefs.

NCEs exert particularly strong effects in aquatic populations (Pressier et al. 2005). This may be due to altered prey behavior or habitat selection having a greater collective impact on community or population dynamics compared to the consumptive effect of predation alone (Ale and Whelan 2008). NCEs are observed in coral reef fishes (Chivers et al. 2008; Hammerschlag et al. 2018; Catano et al. 2016; Davis et al. 2017). Behavioral responses to predation are particularly revealing as organisms can respond quickly to risk, and responses can indicate the status of individuals, populations, and communities in place. Some known behavioral responses to predation risk include schooling (Rieucau et al. 2015), reduced 
foraging rates (Rasher et al. 2017; Madin 2010) and altered habitat use over space and time (Werner et al. 1983; Harvey and White 2017). These NCEs can be studied through the ecology of fear.

The ecology of fear views the predator-prey system as a dynamic game of behavioral responses that have population and community level consequences (Brown et al. 1999). Prey respond to acute and chronic variation in risk when predation risk is predictable and controllable (Creel 2018). However, there are tradeoffs associated with anti-predator defenses (Lima 1988). One way to minimize the cost of these defenses is to respond only when predation risk is high. Under the threat of predation, prey can spend time either avoiding risky places and activities, or by being more vigilant (Wirsing and Ripple 2011). Foraging behavior should reflect both acute and chronic responses to predation risk. Predation risk includes properties of the landscape, and characteristics of both predator and the prey, such as: predator encounter rates, predator lethality, prey escape strategies, and the availability of refugia (Lima and Dill 1989). Prey perceptions of risk are revealed by giving-up densities at experimental food patches (Brown 1988; Brown and Kotler 2004). Spatial variation in risk reveals the prey's landscape of fear (Laundré et al. 2001; Brown et al. 1999; Gaynor et al. 2019), or in our case, a reefscape of fear (sensu Cantano et al. 2017).

Recent studies have used a variety of approaches to investigate the ecology of fear on reefs (Madin 2010; Rasher et al. 2016; Catano et al. 2017; Gil et al. 2018; Nunes 2018; Lester et al. 2020). Here we use the conceptual framework of patch use theory (Charnov 1976) and the giving-up density technique as a standardized assessment of the costs of predation risk associated with foraging across varying habitat types (Brown 1988; Brown and Kotler 2004). We consider how changes in habitat quality influence the perceived predation risk by saddle wrasse on patch coral reefs in Kāne'ohe Bay, O'ahu, Hawai'i. This bay has a long history of coral reef degradation and recovery. Invasive carpeting algae were introduced into the bay in the 1970's and have colonized many of the bay's patch reefs (Bahr et al. 2015), leaving some reefs degraded and others algae free. Although successful conservation and restoration efforts reduced the overall abundance of invasive algae (Nelson et al. 2018), coral reefs may take decades to recover from a degraded state (Berumen and Pratchett 2006).

The goal of this study was to evaluate the tradeoffs of risk and reward on coral reefs. To do this we first assessed fish and benthic communities on patch reefs. Next, we quantified the spatio-temporal variation of risk (the reefscape of fear) of a common Hawaiian coral reef fish across reef habitats. Finally, we assessed tradeoffs in resource availability and predation risk on these reefs. We expected benthic and fish communities to vary with differences in reef quality. We hypothesized that fish will perceive higher predation risk on reefs with reduced coral structure and refuge availability. Consequently, they should use resource patches less intensively and leave them at higher giving-up densities. We also hypothesized that perceived risk will vary within reefs, with greater foraging intensity and lower giving-up densities near coral refugia. Finally, we hypothesized differences in foraging behavior among patch reefs are due to tradeoffs in food availability and safety, which can serve as an integrative assessment of habitat quality from the perspective of inhabitants themselves. According to ideal free distribution and densitydependent habitat selection theory, we expect to find higher fish density on reefs with higher resource 
productivity, and higher giving-up densities on reefs with higher predation risk. We propose that differences in perceived risk and resource availability between reefs will be revealed by the distribution of fish across reefs and their intensity of foraging within experimental food patches.

\section{Methods}

\section{Study Site}

This study was conducted on the shallow patch reefs of Kāne'ohe Bay, O'ahu, Hawai'i during the Summer 2016. Within a $41.4 \mathrm{~km}^{2}$ area, the bay's estuarine system includes a barrier, fringing, and multiple patch reefs (Bahr et al. 2015). The reefscape of fear experiments were conducted on five reefs within southern Kāne'ohe Bay (Reef 12, Reef 13N, Reef 13S, Reef 14, and Reef 16; reef numbers consistent with those used by the Hawai'i Division of Aquatic Resources (Neilson et al. 2014)). These reefs were selected based on the historic presence of invasive algae, Euchema spp. and Kappaphycus spp., and priority status for mitigation efforts (Neilson et al. 2014; Neilson et al. 2018). At the time of the study, a recent die-off of invasive algae resulted in very little macroalgal cover on all study reefs (Neilson et al. 2018). However, the long term effects of habitat degradation were still present. Therefore, we refer to degraded reefs with historic presence of invasive algae as "algae-impacted" (10.16\% - 11.4\% invasive algal cover - Neilson et al. 2014). We refer to healthy reefs with little to no invasive algae as "algae-free." $(0.02 \%-0.18 \%$ invasive algal cover (Neilson et al. 2014); Fig. 1, Fig. 4). Thus, these reefs serve as a natural experiment with varying levels of habitat quality (Reefs 14 and 16 - algae-impacted; Reefs 12, 13N, $13 S$ - algae-free).

\section{Study species}

We studied the saddle wrasse/hīnālea lau wili (Thalassoma duperrey). This fish is a Hawaiian endemic, secondary consumer, and benthic invertivore. Benthic invertivores are important coral reef species for energy transfer as they are abundant, comprising an estimated $27-56 \%$ of fish species on coral reefs (Jones et al. 1991). Based on visual surveys, saddle wrasse are the most abundant mobile secondary consumer on the coral reefs of the main Hawaiian Islands (Heenan 2014). Multiple predator species using diverse hunting strategies prey on wrasses (Parrish 1982). Bluefin trevally/ 'ōmilu (Caranx melampygus) are abundant, open water, pursuit predators in the bay, and dietary analysis suggests that saddle wrasse are a primary component of their diet (Meyer et al. 2001). Other potential predators that feed on small, mobile coral reef fishes include other pursuit predators like scalloped hammerhead pups/mano kihikihi (Sphyrna lewini) (Clark 1971), cryptic ambush predators such as multiple species of lizardfish/'ulae (Ashworth et al. 2014) and devil scorpionfish/nohu 'omakaha (Scorpaenopsis diabolus), invasive predators such as peacock grouper/roi (Cephalopholis argus), stalkers such as crocodile needlefish/'aha (Tylosurus crocodilus) and bluespotted cornetfish/nunu (Fistularia commersonii), and crevice associated ambush predators such as yellowmargin moray/puhi paka (Gymnothorax flavimarginatus), among others.

\section{Benthic Community}


A $10 \mathrm{~m} \times 20 \mathrm{~m}$ grid was randomly selected along the leeward side of each reef, with experimental stations placed 5 meters apart. Photos of the benthos were taken at each experimental station ( 15 stations per reef). Images were analyzed using the program Coral Point Count with Excel extensions (CPCe) (Kohler and Gil 2006). Sixteen randomized points were projected onto each image and benthic cover type was identified for each point (see S.I. Table S1 for list of benthic variables). Benthos data were used to calculate benthic community composition, benthic diversity, and coral cover at each station.

Three-dimensional (3D) reconstructions of coral reefs were used to quantify coral rugosity using structure-from-motion (sfm) techniques (Young et al. 2017). Following Raoult et al. (2016), a GoPro Hero4 camera was used to take continuous rapid-fire images of the benthos along two, $25 \mathrm{~m}$ transects on the leeward and windward sides of the study patch reefs (4 transects per reef). This resulted in an average of 209.25 images/transect $( \pm 7.90$ SEM, $n=20)$, which were then used to create 3D models of the reef using Agisoft Photoscan (Agisoft LLC). Linear rugosity was analyzed from the 3D models using Rhinoceros 3D ("Rhino"; Robert McNeel \& Associates) "Meshlntersect" command, and the Rhino Python "Rugosity" script (Young et al. 2017).

Fish Community and T. duperrey Population: Belt transect surveys (25m long x $4 \mathrm{~m}$ swath) were conducted on each patch reef during daylight hours to assess $T$. duperrey populations and the fish community composition. A total of four transects were surveyed per reef with transects haphazardly placed across 2 leeward sites and 2 windward sites. All fishes within the belt transect were counted and identified to species. Belt transect data were not used to estimate predator populations because inherent biases in this type of data may lead to an overestimation of transitory predators and an underestimate of cryptic benthic predators (Caldwell et al. 2016). Therefore, we relied on the giving-up density approach to quantify perceived predation risk (Brown 1988).

Measuring Giving-up Densities and Reefscapes of Fear. The giving-up density (GUD) technique is commonly used to quantify the costs of predation risk associated with foraging at an experimental food patch with diminishing returns (Brown 1988). In this study, we used krill "burritos", which consisted of 4 krill placed within a substrate and wrapped in polyurethane coated mesh. Krill burritos were used to measure the GUDs of saddle wrasse at 15 stations (each 5 meters apart) forming a $10 \mathrm{~m} \times 20 \mathrm{~m}$ experimental array on each of the 5 study reefs. Krill burritos were placed at each station and $T$. duperrey were allowed to forage from the patches for 4 daylight hours over a minimum of 10 experimental days (with the exception of 4 stations which were measured over 4 days $(n=3)$, and 9 days $(n=1))$. After the 4 hour period, the krill burrito was removed and the GUD (the remaining krill within the food patch) was quantified to nearest quarter krill. Food removal from the krill burrito generates diminishing returns: as more food is removed, the harder it becomes to access the remaining food items. Depleting a krill burrito was akin to a continuous process as the wrasse incrementally bite pieces from a given krill.

\section{Statistical Analyses}

We ran all statistical analyses using R Project for Statistical Computing version 3.3.3 (R Development Core Team 2018; package citations in Appendix S1). 
A permutational multivariate analysis of variance (PERMANOVA) was used to test for differences in benthic communities between patch reefs by partitioning the Euclidean distance matrix by species with adonis in the vegan package. Finally, we tested for homogeneity of multivariate dispersions using betadisper and permutest functions in the vegan package. To visualize differences in benthic communities on patch reefs we ran a principal component analysis (PCA) on Hellinger-transformed abundance data using decostand in the vegan package, and prcomp in the ggord package. We assessed differences in coral cover and rugosity between reefs with generalized linear models (GLMs) with Gaussian error structure using the $g / m$ function in the base R package. We tested for significance between our GLM and the null model using the anova function in the base R package.

We calculated fish diversity (inverse Simpson's index) using the diversity function in the vegan package. Fish diversity and species richness were compared with a GLM using the $g / m$ function in the base R package. We used fish species abundance data to assess patch reef fish communities using the same multivariate analyses as described for the benthic communities above. We calculated the 10 most common species in our belt transect surveys (species present in highest numbers for combined data). We then calculated relative abundances of the 10 most common species, with all other species classified as "other". We investigated common standardization approaches for T. duperrey abundance data using the decostand function in the vegan package. Since no transformations were necessary (see S.I.), we assessed differences in untransformed $T$. duperrey density (individuals $/ 100 \mathrm{~m}^{2}$ ) using GLM with Gaussian error structure using the $\mathrm{g} / \mathrm{m}$ function in the base R package. We tested for significance between our GLM and the null model using the anova function in the base R package.

To assess differences in GUDs, we used linear mixed effects models (LMMs) with reef and station nested within reef as fixed effects, and experimental day nested within reef as random effects using the Imer function in the Ime4 package. We used a multivariate analysis of variance (MANOVA) to test if coral cover and benthic diversity differ significantly between reefs. Next, we used an analysis of covariance (ANCOVA) using the aov function in the stats package to assess how coral cover and benthic diversity may have impacted average station GUD. Since there was no interaction between the covariates, we removed the interaction term and used only the main effects. We used coral cover and benthic diversity as covariates and reef as the grouping variable.

Mean GUDs of each station were used to create reefscapes of fear heatmaps using the plot_ly function in the plotly package. Contours represent lines of equal mean GUD. All other graphs and maps were created using ggplot2, ggpubr, and ggmap

\section{Results}

\section{Benthic Community}

Reefs varied in benthic community composition by location (PERMANOVA, $F_{4,67}=12.213 ; P=0.001$ ) and dispersion $\left(F_{4,67}=2.636, P=0.04\right)$. Principal component analysis of benthic composition showed clear 
separation of the two algae-impacted reefs from the three algae-free reefs (Fig. 2A). PC1 and PC2 explained $41.05 \%$ and $21.8 \%$ of the variation in benthic community composition, respectively. While Montipora spp. coral is more characteristic of algae-free reefs, Porites spp. coral is more characteristic of algae-impacted reefs (Fig. 2A). Dead coral occurred at a greater density on algae-impacted than on algaefree reefs.

Reefs varied by percent coral cover (ANOVA, $F_{4,67}=11.63$, $P<0.001$; Fig. 2B) in Kāne'ohe Bay. Algae-free reefs $(12,13 \mathrm{~N}, 13 \mathrm{~S})$ had significantly more coral cover than algae-impacted reefs (14 and 16) $(P<0.001)$. Reef $13 \mathrm{~S}$ had the highest coral cover with 2.6 times more coral cover than Reef 14 . Within reefs, there was no significant relationship between coral cover and benthic diversity (Appendix S1: Table S7), though we did observe trends where benthic diversity declined with increased coral cover on algae-free reefs. This is because they were mostly dominated by one or two species (i.e. Montipora capitata). Algae-impacted reefs had a trend of increased diversity as coral cover increased.

Coral rugosity differed among patch reefs (ANOVA, $F_{4,115}=12.07, P<0.001$; Fig. 2 C). Reef 12 had the lowest rugosity score (lowest structural complexity), while all other reefs had similar rugosity, likely reflecting the dominance of "mounding" coral morphotypes on these reefs.

Fish Community and T. duperrey Density. According to the visual belt transect surveys of the 5 reefs, the most common species (calculated by the total number of transects wherein a species was observed) were Stethojulis balteata (belted wrasse/'omaka), Chlorurus spilurus (bullethead parrotfish/uhu), Gomphosus varius (bird wrasse/hinalea i'iwi, Scarus psittacus (palenose parrotfish/uhu), and T. duperrey. There were no significant differences in the species diversity or richness among reefs (Appendix S1: Fig. S3, Table S11, Table S12). Fish community composition differed with location (PERMANOVA: $F_{4,15}=$ $1.88, P=0.003)$, however there was no dispersion effect $\left(F_{4,15}=0.985, P=0.439\right)$. Principal component analysis of fish communities separated Reef 16 from all others. PC1 (30.63\% of the variance) was associated with increasing representation of the herbivore parrotfish S. psitticus (Fig. 3A). PC2 (16.03\% of the variance) was associated with a shift away from fish communities dominated by saddle wrasse, $T$. duperrey, to ones dominated by damselfish, S. marginatus.

Saddle wrasse were commonly observed on all experimental reefs in this study, with a relative abundance ranging from $7.6-45.0 \%$ of the total fish community. Saddle wrasse density differed among reefs (ANOVA: $F_{4,5}=3.563, P=0.047$; Fig. $3 \mathrm{~B}$ ). Saddle wrasse density was greatest on algae-free $13 \mathrm{~S}$, intermediate on algae-free reefs 12 and $13 \mathrm{~N}$, and algae-impacted reef 14, and lowest on algae-impacted reef 16 .

\section{Reefscape of Fear}

There was a slight effect of station (experimental food patch location) within reef $\left(F_{70,694.5}=5.59, P=\right.$ 0.061 ) on the GUD (Fig. 4). GUDs differed significantly among reefs $\left(F_{4,696.7}=5.59, P<0.001\right)$. Reef 16 (algae-impacted) had the highest perceived predation risk, with a $42.1 \%$ decrease foraging intensity and 
increase in GUD compared to Reef 13S (algae-free), which had the lowest perceived predation risk and highest foraging intensity. Perceived predation risk did not differ among reefs $12,13 \mathrm{~N}$ (both algae-free), and 14 (algae-impacted). GUDs did not vary with microhabitat features of coral cover or benthic diversity at each station (ANCOVA, $F_{4,55}=0.002, P=0.97 ; F_{4,55}=0.195, P=0.66$ ).

\section{Discussion}

The ecology of fear provides insights into how a common Hawaiian coral reef fish perceives its environment. Degraded, or algae-impacted, reefs differ in benthic community composition (Fig. 2), yet were mostly similar to healthy, or algae-free, reefs in terms of fish communities (Fig. 3). Saddle wrasse were common on all experimental patch reefs. Despite this, they perceive differences in predation risk among reefs (Fig. 4). Specifically, saddle wrasse perceive predation risk across larger spatial scales, rather than microhabitats. Patch reefs are scary if they are degraded. Habitat degradation, when viewed from the point of view of the fish, influences the predator-prey dynamics of this coral reef system by altering the reefscape of fear.

\section{Fear on coral reefs}

We found habitat degradation alters the fear of predation of a common Hawaiian fish. Fish reduced foraging in experimental food patches on algae-impacted reefs, indicating perceived risk of predation increased on the degraded habitats (Fig. 4). Our results are consistent with other behavioral indicators such as reduced foraging or reduced flight initiation distances with increased risk (Madin et al. 2010; Harvey and White 2017). Therefore, habitat degradation is an important factor that alters the fear of predation on coral reefs.

Scale plays an important role in how fish perceive and respond to predation risk. Prior studies of fear responses of coral reef fishes have been done at smaller scales to assess responses to immediate predator presence (Catano et al. 2016; Madin et al. 2010; Lester et al. 2020). While other studies show that behavioral responses to risk can vary at larger scales, moving away from contiguous reef habitat (Gil et al. 2016), with tides (Rasher et al. 2018), and even at scales large enough to be visible from space (Madin et al. 2019).

Surprisingly, saddle wrasse did not perceive significant variation in predation risk at small scales within reefs associated with microhabitat features. Rather, the wrasses perceived differences in predation risk at macro-habitat scales. This may be due to the anti-predator strategies employed by the saddle wrasse.

First and foremost, saddle wrasse manage predation risk by diel activity patterns. Saddle wrasse are 'early to bed' and one of the last fishes to resume activity in the morning, thus almost entirely avoiding the riskiest times of dawn or dusk (Hobson 1972). Once active, wrasse swim higher in the water column than other species (Fulton et al. 2001). This likely emphasizes their advantages. Like other wrasse (Labridae) species, saddle wrasse are highly visual (Barry and Hawryshyn 1999) and relatively fast swimmers (Walker and Westneat 1997). Their strategy to avoid predation is to detect predators and quickly swim 
away. Therefore, the availability of nearby refugia at a foraging site within a reef's interstices may not influence their perceptions of risk. Instead, the availability of refuge on the patch reef as a whole may be a more important factor for perceived risk.

How a fish perceives risk may vary with species based on their particular anti-predator adaptations. While we focused on the behaviors of saddle wrasse in this study, we also found a difference in the fish community composition on risky reefs. Interestingly, there was a higher abundance of fish with morphological anti-predator defenses of spines or keels, such as Moorish idols (Zanclidae), surgeonfishes (Acanthuridae) and butterflyfishes (Chaetodontidae), on the riskiest reef, reef 16 . This suggests that predation risk may influence community level responses.

We note similarities between anti-predator responses in marine and terrestrial systems (Wirsing and Ripple 2010). For instance, both terrestrial and marine prey exhibit morphological and behavioral responses to predation risk. Prey defend themselves from predators with colors, structures, chemicals, grouping behaviors, or altered activity patterns. In particular, regardless of marine or terrestrial environment, prey will reduce foraging activity in response to risk, there is spatial heterogeneity in perceived risk, and the landscape of fear may vary with anthropogenic influence. Unlike terrestrial systems, marine prey must contend with risk varying in an aqueous environment. This means there will be differences in the visual and chemical cues a prey receives. It also means that risk may vary in a 3dimensions (Harvey and White 2017; Lester et al. 2020). Finally, prey on pristine coral reefs must cope with high biomass of fierce predators, which is not typical of terrestrial predator-prey systems (Malone et al. 2020).

Similarly to this study, spatial scale is also an important factor in many terrestrial studies on predation risk (Morgan et al. 1997; Shrader et al. 2007). Different prey species may assess risk at different spatial scales (Berris 1997). Unlike many terrestrial studies on predation risk, the variability in risk in our study occurred at much larger spatial scales. This may be due to predation being diffuse on coral reefs, coming from a diverse assemblage of piscivorous fishes that use a wide variety of predation strategies.

According to published dietary analyses, the main predators of saddle wrasses are bluefin trevally. Bluefin trevally are roving predators that spend their day patrolling one patch reef and move between reefs at night (Holland et al. 1996), making the risk of predation somewhat unpredictable day to day. We observed acute behavioral responses to the presence of bluefin trevally, but they did not result in significant differences in GUDs. GUDs are therefore a reliable method to quantify chronic predation risk on reefs.

We considered the possibility that GUDs were not, in fact, quantifying predation risk on reefs, but instead quantifying other factors such as resource availability. The average GUD between reefs correlated positively with wrasse densities, which may seem to indicate that the GUD is an indicator of productivity. According to optimal foraging theory, however, fish living on reefs with high resource availability should have high GUDs, while fish on reefs with low resource availability should have low GUDs. This is because the marginal value of the resource within the food patch is higher for fish on low productivity reefs. We 
did not observe these trends, which supports our conclusion that the GUD was a measure of predation risk.

\section{Impacts of habitat degradation}

We demonstrated the long-lasting impact of an altered reefscape of fear due to habitat degradation caused by the chronic presence of invasive algae. Invasive algae, Euchema spp. and Kappaphycus spp., were uncommon on study reefs during the 2016 season because of herbivore biocontrol (Neilson et al. 2018). Even though the invasive algae were not a major component of the benthic community at the time of this study, their impact was still visible through the higher amount of dead coral (Fig. 2) observed on Reef 16 . The unseen ecological impact of habitat degradation is the reduction in foraging behaviors across patch reefs. Changes to this non-consumptive effect of predation will impact the predator-prey dynamics of the system.

Habitat degradation may alter the directionality of non-consumptive effects. Here, we show how the nonconsumptive effects of predation can also be impacted from the "bottom-up". Altered habitat due to degradation changes the refuge availability and thereby the predation risk perceived across the reef. In contrast, non-consumptive effects can be altered from the "top-down". Changes in predator populations drive anti-predator responses in prey and result in trophic cascades (Madin et al. 2019). It is unlikely the differences in predation risk in this study were due to differences in predator populations, as reefs were in close proximity (within $1.5 \mathrm{~km}$ of each other) and none of the reefs are within protected areas.

Tradeoffs between resource availability and safety - conservation implications: Habitat degradation may influence the balance between resource availability and safety. When approached through the lens of tradeoffs, we can classify coral reefs into ecologically relevant categories based on resource availability and predation risk (Appendix S1: Table S21) (Kotler et al. 2016). This classification approach provides a complementary metric to classical reef assessments. Saddle wrasse are good candidate species for this approach as they are a common benthic invertivore and the primary species filling this niche on Hawaiian reefs. In this study, wrasse density provides a metric of invertebrate productivity (Fig. 3C) and GUDs a metric of predation risk (Fig. 4). Through the concepts of ideal free distribution theory and density dependent habitat selection, we expect resource availability to be reflected through a positive correlation with wrasse abundance. According to patch use theory, GUDs in risky habitats will be higher than those in safe habitats. Based on wrasse abundance and GUDs we can classify the reefs in our study. Algaeimpacted reef 16 is an inferior reef for saddle wrasse as it has the lowest density of saddle wrasse and the highest risk. Algae-free reef $13 \mathrm{~S}$ is core wrasse habitat; it has the highest wrasse density and lowest risk. Interestingly, saddle wrasse did not view algae-impacted reef 14 as being inferior habitat (risky and resource poor), but instead a core predator habitat (risky and productive). This may be due to the high amount of coral rubble and sand on the reef which saddle wrasse preferentially use for foraging (M.A.M unpublished data). Reefs 12 and $13 \mathrm{~N}$ can both be categorized as refuge habitat, as they are relatively safe but resource poor. 
This habitat classification approach according to predation risk and resource productivity has conservation implications and can serve as a direct behavioral indicator of populations and communities (Kotler et al. 2016). This paradigm has been successfully applied to several terrestrial systems (Reid 2004; Vickery 2010; Morris and Dupuch 2012; Abu Baker and Brown 2013). In common with these terrestrial applications, the wrasse's distribution and behavior revealed habitat quality. In contrast, we investigated habitat degradation impacts on food and safety tradeoffs. By considering tradeoffs, managers can assess habitats and the efficacy of conservation efforts from the point-of-view of inhabitants themselves. Coral reefs are threatened worldwide and management strategies should focus on the ecological implications of habitat degradation. We advocate GUDs as a standardized technique, which complements other metrics.

\section{Conclusion}

Habitat degradation alters the reefscape of fear on coral reefs. Increased predation risk on degraded reefs alters predator-prey interactions and may fundamentally alter how predation structures populations and communities. We advocate taking an integrative approach to study the ecology of fear on coral reefs. In particular, studies of habitat degradation, as measured by fish abundances, coral properties, and resource abundances, would benefit from a measure of giving-up densities. Allowing fish to reveal their perceptions of habitat through their patch use behavior provides a critical piece of information for both assessing and monitoring reefs.

\section{Declarations}

\section{Acknowledgements:}

We thank Brian Bowen for his sponsorship of MAM at the Hawaii Institute of Marine Biology. We thank Brian Bowen, Evan Barba, Stephanie Chancellor, Sarah Leicht Severino, Devi Veytia, the ToBo Lab and the Brown Lab for field support, discussions and comments.

Funding: Funding to MAM came from University of Illinois at Chicago Hadley Award, American Museum of Natural History Lerner-Gray Marine Research Grant, and generous crowd-sourcing donations via experiment.com.

Conflicts of interest/Competing interests: none

Ethics approval: This work was performed under UH IACUC protocol \#15-2271 and SAP 2016-52.

Consent to participate: not applicable

Consent for publication (include appropriate statements): not applicable 
Availability of data and material (data transparency): The datasets used and/or analysed during the current study are available from the corresponding author on reasonable request. Code availability (software application or custom code): The code used to for this study are available from the corresponding author upon reasonable request

\section{References}

1. Abu Baker MA, Brown JS (2014) Foraging and habitat use of common duikers, Sylvicapra grimmia, in a heterogeneous environment within the Soutpansberg, South Africa. Afr J Ecol 52(3):318-327

2. Ale SB, Whelan CJ (2008) Reappraisal of the role of big, fierce predators! Biodivers Conserv 17(4):685-690

3. Almany GR (2004) Does increased habitat complexity reduce predation and competition in coral reef fish assemblages? Oikos 106(2):275-284

4. Ashworth EC, Depczynski M, Holmes TH, Wilson SK (2014) Quantitative diet analysis of four mesopredators from a coral reef. J Fish Biol 84(4):1031-1045

5. Bahr KD, Jokiel PL, Toonen RJ (2015) The unnatural history of Kāne 'ohe Bay: coral reef resilience in the face of centuries of anthropogenic impacts.PeerJ, 3, e950

6. Baker AC, Glynn PW, Riegl B (2008) Climate change and coral reef bleaching: An ecological assessment of long-term impacts, recovery trends and future outlook. Estuar Coast Shelf $\mathrm{S}$ 80(4):435-471

7. Barry KL, Hawryshyn CW (1999) Spectral sensitivity of the Hawaiian saddle wrasse, Thalassoma duperrey, and implications for visually mediated behaviour on coral reefs. Environ Biol Fish 56(4):429-442

8. Berris LS (1997) Mechanisms affecting foraging decisions of the raccoon (Procyon lotor) in northeastern Illinois. - MS dissertation, Univ. of Illinois at Chicago, Chicago

9. Brown JS (1988) Patch use as an indicator of habitat preference, predation risk, and competition. Behav Ecol Sociobiol 22(1):37-47

10. Berumen ML, Pratchett MS (2006) Recovery without resilience: persistent disturbance and long-term shifts in the structure of fish and coral communities at Tiahura Reef, Moorea. Coral Reefs 25(4):647-653

11. Brown JS (1999) Vigilance, patch use and habitat selection: foraging under predation risk. Evol Ecol Res 1(1):49-71

12. Brown JS, Laundré JW, Gurung M (1999) The ecology of fear: optimal foraging, game theory, and trophic interactions. J Mammal 80(2):385-399

13. Brown JS, Kotler BP (2004) Hazardous duty pay and the foraging cost of predation. Ecol Lett 7(10):999-1014

14. Caldwell ZR, Zgliczynski BJ, Williams GJ, Sandin SA (2016) Reef fish survey techniques: assessing the potential for standardizing methodologies.PloS One, 11(4), e0153066 
15. Catano LB, Rojas MC, Malossi RJ, Peters JR, Heithaus MR, Fourqurean JW, Burkepile DE (2016) Reefscapes of fear: predation risk and reef heterogeneity interact to shape herbivore foraging behaviour. J Anim Ecol 85(1):146-156

16. Charnov EL (1976) Optimal foraging, the marginal value theorem. Theor Popul Biol 9(2):129-136

17. Chivers DP, Zhao X, Brown GE, Marchant TA, Ferrari MC (2008) Predator-induced changes in morphology of a prey fish: the effects of food level and temporal frequency of predation risk. Evol Ecol 22(4):561-574

18. Clark TA (1971) The ecology of the scalloped hammerhead shark (Sphyrna lewini) in Hawaii. Pac Sci 15:15-83

19. Coker DJ, Pratchett MS, Munday PL (2009) Coral bleaching and habitat degradation increase susceptibility to predation for coral-dwelling fishes. Behav Ecol 20(6):1204-1210

20. Creel S (2018) The control of risk hypothesis: reactive vs. proactive antipredator responses and stress mediated vs. food mediated costs of response. Ecol Lett 21(7):947-956

21. Davis K, Carlson PM, Bradley D, Warner RR, Caselle JE (2017) Predation risk influences feeding rates but competition structures space use for a common Pacific parrotfish. Oecologia 184(1):139-149

22. Dudgeon D, Arthington AH, Gessner MO, Kawabata ZI, Knowler DJ, Lévêque C, Naiman RJ, PrieurRichard AH, Soto D, Stiassny ML, Sullivan CA (2006) Freshwater biodiversity: importance, threats, status and conservation challenges. Biol Rev 81(2):163-182

23. Feary DA, Almany GR, Jones GP, McCormick MI (2007) Coral degradation and the structure of tropical reef fish communities. Mar Ecol Prog Ser 333:243-248

24. Fulton C, Bellwood D, Wainwright $P$ (2001) The relationship between swimming ability and habitat use in wrasses (Labridae). Mar Biol 139(1):25-33

25. Gaynor KM, Brown JS, Middleton AD, Power ME, Brashares JS (2019) Landscapes of fear: spatial patterns of risk perception and response. Trends Ecol Evol 34(4):355-368

26. Gil MA, Zill J, Ponciano JM (2017) Context-dependent landscape of fear: algal density elicits risky herbivory in a coral reef. Ecology 98(2):534-544

27. Gorospe KD, Donahue MJ, Heenan A, Gove JM, Williams ID, Brainard RE (2018) Local biomass baselines and the recovery potential for Hawaiian coral reef fish communities. Frontiers in Marine Science 5:162

28. Graham NAJ, Nash KL (2013) The importance of structural complexity in coral reef ecosystems. Coral Reefs 32(2):315-326

29. Graham NA, Jennings S, MacNeil MA, Mouillot D, Wilson SK (2015) Predicting climate-driven regime shifts versus rebound potential in coral reefs. Nature 518(7537):94-97

30. Hammerschlag N, Barley SC, Irschick DJ, Meeuwig JJ, Nelson ER, Meekan MG (2018) Predator declines and morphological changes in prey: evidence from coral reefs depleted of sharks. Mar Ecol Prog Ser 586:127-139 
31. Harvey BC, White JL (2017) Axes of fear for stream fish: water depth and distance to cover. Environ Biol Fish 100(5):565-573

32. Heenan A, Ayotte P, Gratabley A, Lino K, McCoy K, Zamzow J, Williams ID (2014) Pacific reef assessment and monitoring program. Ecological monitoring 2012-2013: reef fishes and benthic habitats of the Main Hawaiian Islands, American Samoa, and Pacific Remote Island Areas. Pacific Islands Fisheries Science Center, Data Report, p 112. PIFSC Data Report, DR-14-003

33. Hobson ES (1972) Activity of Hawaiian reef fishes during the evening and morning transitions between daylight and darkness. Fish B-NOAA 70(3):715-740

34. Holland KN, Lowe CG, Wetherbee BM (1996) Movements and dispersal patterns of blue trevally (Caranx melampygus) in a fisheries conservation zone. Fish Res 25(3-4):279-292

35. Jones GP, Ferell DJ, Sale PF (1991) Fish predation and its impact on the invertebrates of coral reefs and adjacent sediments. The ecology of fishes on coral reefs. P.F. Sale Academic Press, San Diego, California, USA, pp 156-179

36. Kohler KE, Gill SM (2006) Coral Point Count with Excel extensions (CPCe): A Visual Basic program for the determination of coral and substrate coverage using random point count methodology. Comput Geosci 32(9):1259-1269

37. Kotler BP, Morris DW, Brown JS (2016) Direct behavioral indicators as a conservation and management tool. in Conservation Behavior: Applying Behavioral Ecology to Wildlife Conservation and Management, 21, 307

38. Laundré JW, Hernández L, Altendorf KB (2001) Wolves, elk, and bison: reestablishing the "landscape of fear" in Yellowstone National Park, USA. Can J Zool 79(8):1401-1409

39. Lester EK, Langlois TJ, Simpson SD, McCormick MI, Meekan MG (2020) The hemisphere of fear: the presence of sharks influences the three dimensional behaviour of large mesopredators in a coral reef ecosystem. Oikos 129(5):731-739

40. Lima SL, Dill LM (1990) Behavioral decisions made under the risk of predation: a review and prospectus. Can J Zool 68(4):619-640

41. Madin EM, Gaines SD, Warner RR (2010) Field evidence for pervasive indirect effects of fishing on prey foraging behavior. Ecology 91(12):3563-3571

42. Madin EM, Harborne AR, Harmer AM, Luiz OJ, Atwood TB, Sullivan BJ, Madin JS (2019) Marine reserves shape seascapes on scales visible from space. P R Soc B, 286(1901), 20190053

43. Malone MA, Halloway AH, Brown JS (2020) The ecology of fear and inverted biomass pyramids. Oikos 129(6):787-798

44. Meyer CG, Holland KN, Wetherbee BM, Lowe CG (2001) Diet, resource partitioning and gear vulnerability of Hawaiian jacks captured in fishing tournaments. Fish Res 53(2):105-113

45. Mitchell MD, Harborne AR (2020) Non-consumptive effects in fish predator-prey interactions on coral reefs. Coral Reefs. https://doi.org/10.1007/s00338-020-01920-y 
46. Morgan RA, Brown JS, Thorson JM (1997) The effect of spatial scale on the functional response of fox squirrels. Ecology 78(4):1087-1097

47. Morris DW, Dupuch A (2012) Habitat change and the scale of habitat selection: shifting gradients used by coexisting Arctic rodents. Oikos 121(6):975-984

48. Neilson BJ, Blodgett J, Gewecke C, Stubbs B, Tejchman A (2014) Kaneohe Bay, Oahu SnapAssessment Report. Hawai'i Department of Land and Natural Resources. https://dlnr.hawaii.gov/ais/files/2014/06/KbaySnapAssessReportMay2014.pdf

49. Neilson BJ, Wall CB, Mancini FT, Gewecke CA (2018) Herbivore biocontrol and manual removal successfully reduce invasive macroalgae on coral reefs.PeerJ, 6, e5332

50. Newbold T, Hudson LN, Hill SL, Contu S, Lysenko I, Senior RA, Börger L, Bennett DJ, Choimes A, Collen B, Day J (2015) Global effects of land use on local terrestrial biodiversity. Nature 520(7545):45-50

51. Nunes JAC, Costa Y, Blumstein DT, Leduc AO, Dorea AC, Benevides LJ, Sampaio CL, Barros F (2018) Global trends on reef fishes' ecology of fear: Flight initiation distance for conservation. Mar Environ Res 136:153-157

52. Oksanen $\mathrm{J}(2011)$ Multivariate analysis of ecological communities in R: vegan tutorial. R package version 1(7):1-43

53. Parrish JD, Norris JE, Callahan MW, Callahan JK, Magarifuji EJ, Schroeder RE (1986) Piscivory in a coral reef fish community. In Contemporary studies on fish feeding: the proceedings of GUTSHOP'84 (pp. 285-298). Springer, Dordrecht

54. Pratchett MS, Hoey AS, Wilson SK, Messmer V, Graham NA (2011) Changes in biodiversity and functioning of reef fish assemblages following coral bleaching and coral loss. Diversity 3(3):424452

55. Pratchett MS, Hoey AS, Wilson SK (2014) Reef degradation and the loss of critical ecosystem goods and services provided by coral reef fishes. Curr Opin Env Sust 7:37-43

56. Preisser EL, Bolnick DI, Benard MF (2005) Scared to death? The effects of intimidation and consumption in predator-prey interactions. Ecology 86:501-509

57. Rasher DB, Hoey AS, Hay ME (2017) Cascading predator effects in a Fijian coral reef ecosystem. Sci Rep-UK 7(1):1-10

58. Rieucau G, Boswell KM, Kimball ME, Diaz G, Allen DM (2015) Tidal and diel variations in abundance and schooling behavior of estuarine fish within an intertidal salt marsh pool. Hydrobiologia 753(1):149-162

59. Shrader MA, Kotler BP, Brown JS, Kerley GIH (2008) Providing water for goats in arid landscapes: effects on feeding effort with regard to time period, herd size and secondary compounds. Oikos 117(3):466-472

60. Vickery WL, Rieucau G, Jean Doucet G (2011) Comparing habitat quality within and between environments using giving up densities: an example based on the winter habitat of white-tailed deer Odocoileus virginianus. Oikos 120(7):999-1004 
61. Ward-Paige C, Flemming JM, Lotze HK (2010) Overestimating fish counts by non-instantaneous visual censuses: consequences for population and community descriptions.PLoS One, 5(7), e11722

62. Werner EE, Gilliam JF, Hall DJ, Mittelbach GG (1983) An experimental test of the effects of predation risk on habitat use in fish. Ecology 64(6):1540-1548

63. Westneat M, Walker J (1997) Motor patterns of labriform locomotion: kinematic and electromyographic analysis of pectoral fin swimming in the labrid fish Gomphosus varius. J Exp Biol 200(13):1881-1893

64. Wilson SK, Fisher R, Pratchett MS, Graham NAJ, Dulvy NK, Turner RA, Cakacaka A, Polunin NV, Rushton SP (2008) Exploitation and habitat degradation as agents of change within coral reef fish communities. Global Change Biol 14(12):2796-2809

65. Wirsing AJ, Ripple WJ (2011) A comparison of shark and wolf research reveals similar behavioral responses by prey. Front Ecol Environ 9(6):335-341

66. Young GC, Dey S, Rogers AD, Exton D (2017) Cost and time-effective method for multi-scale measures of rugosity, fractal dimension, and vector dispersion from coral reef 3D models.PloS One, 12(4), e0175341

\section{Figures}



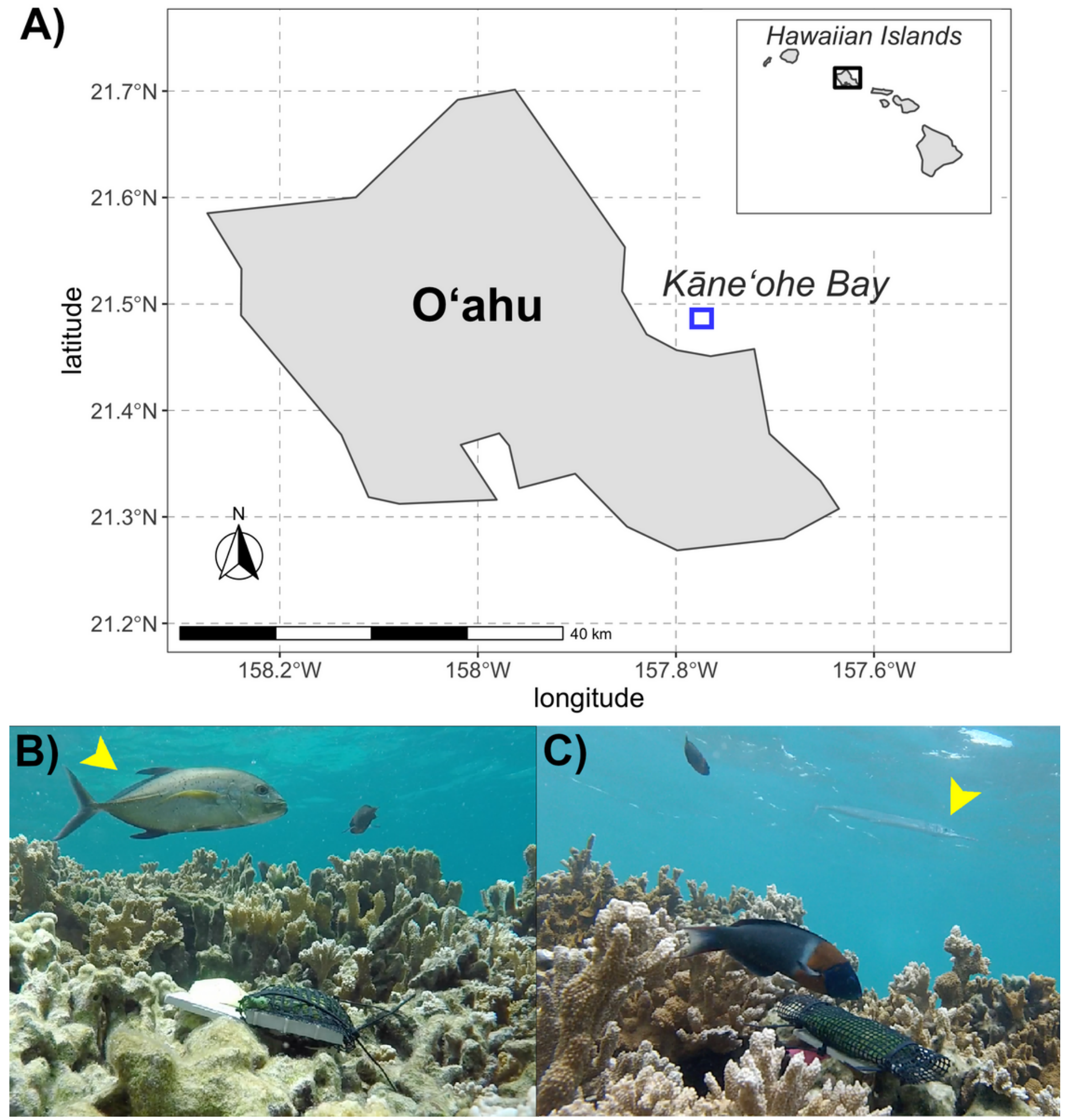

\section{Figure 1}

Map of Kāne'ohe Bay, O'ahu, Hawai'i with study area indicated by black box (See Fig. 4). Top right: T. duperrey foraging at experimental food patch with predator crocodile needlefish/'aha (Tylosurus crocodilus). Bottom right: T. duperrey at experimental food patch as predator bluefin trevally/ 'ōmilu (Caranx melampygus) swims past. 

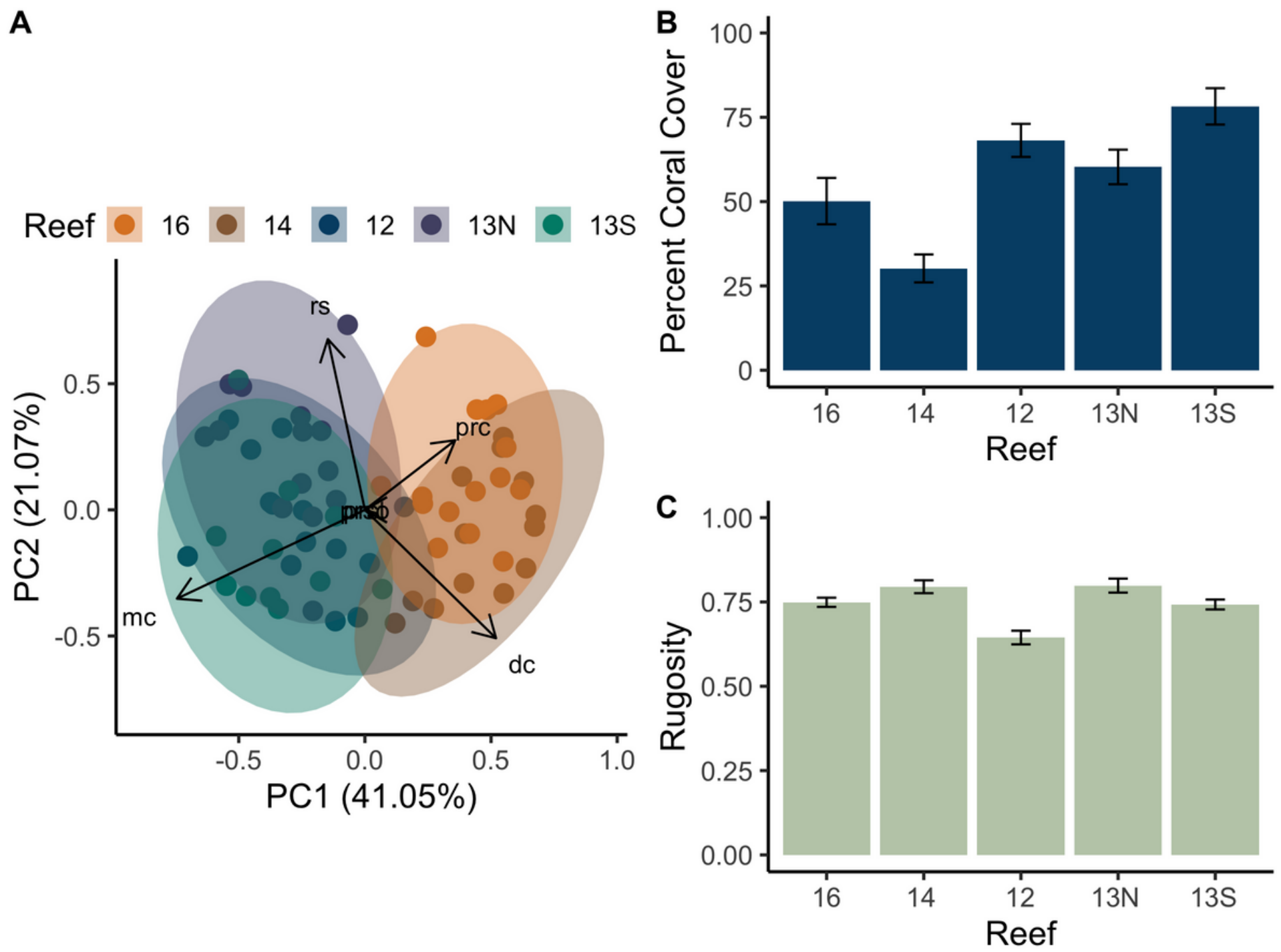

Figure 2

A) Patch reefs in Kāne'ohe Bay, O'ahu, Hawai'i have different benthic communities due to invasive algae. Benthic communities on Reefs 14 and 16 (algae-impacted) differed from all algae-free patch reef communities. The analysis included 18 benthic variables; vectors are shown for variables that contribute to differences in the PCA space $(\mathrm{dc}=$ dead coral, $\mathrm{mc}=$ Montipora capitata, $\mathrm{prc}=$ Porites $\mathrm{sp} ., \mathrm{rs}=$ rock/sand). B) Percent coral cover (mean $\pm S E M ; n=4$ ) among 5 patch reefs in Kāne'ohe Bay, O'ahu, Hawai'i. Reefs 14 and 16 (algae-impacted) had lower coral cover than reefs 12, 13N, $13 \mathrm{~S}$ (algae-free). C) Rugosity (mean \pm SEM; $n=4$ ) among 5 reefs. 
A
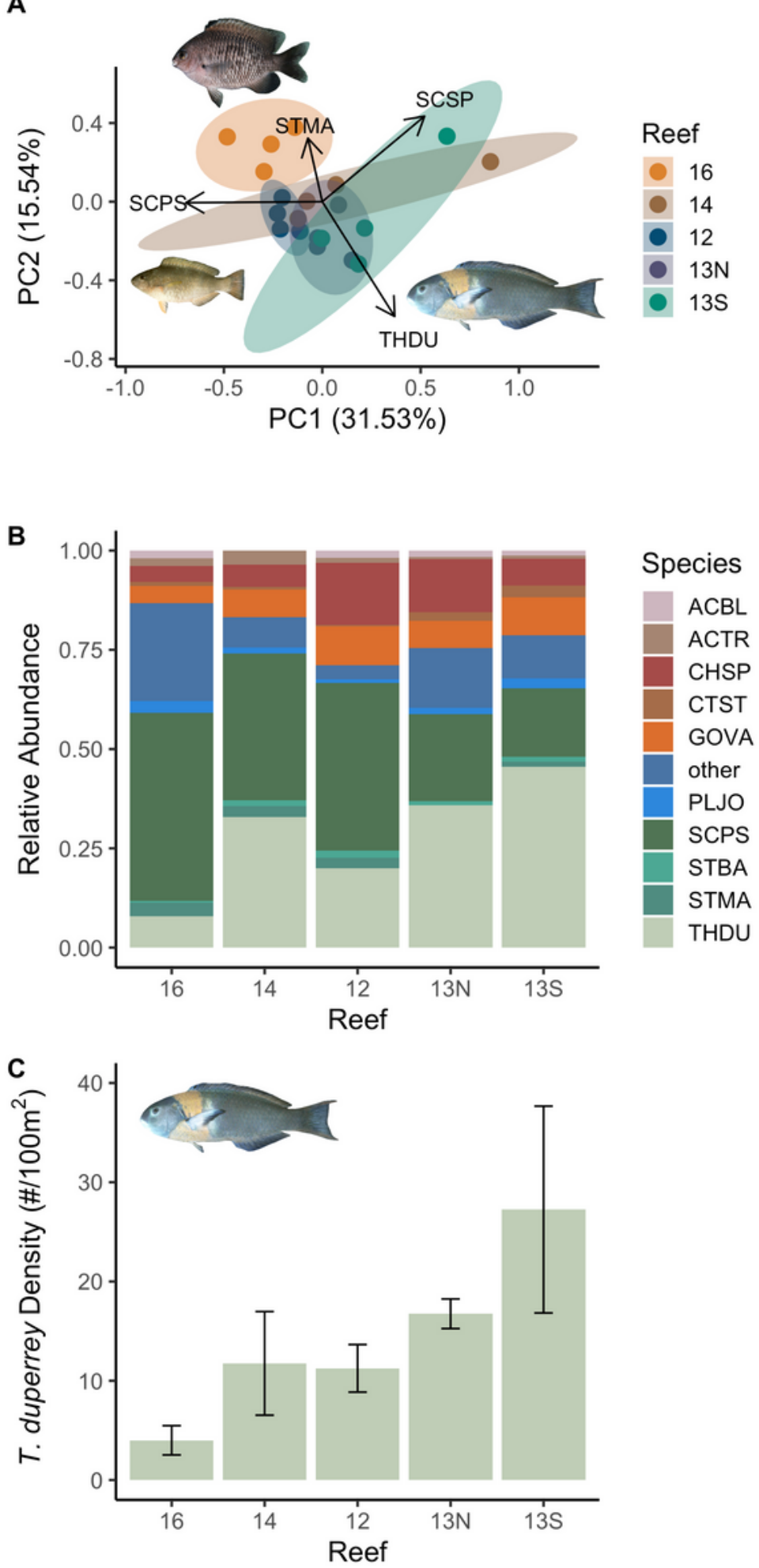

Figure 3

A) Patch reefs in Kāne'ohe Bay, O'ahu, Hawai'i have mostly similar fish communities. The fish community on Reef 16 (algae impacted) differs from all other experimental patch reef communities. The analysis incorporates the densities of 34 fish species with vectors shown for species that contribute to differences in the PCA space (THDU = Thalassoma duperrey, SCPS = Scarus psittacus, SCSP = Scarus sp., STMA = Stegastes marginatus). B) Relative abundances for ten most common fish species on 5 study reefs. 
Species codes in Appendix Table S10. C) T. duperrey density (number of individuals/100m2) (mean \pm SEM) on algae-impacted reefs (Reef 16 and 14) and algae-free reefs (Reefs 12, 13N, and 13S). Fish images by J. Randall via Fishbase.org.

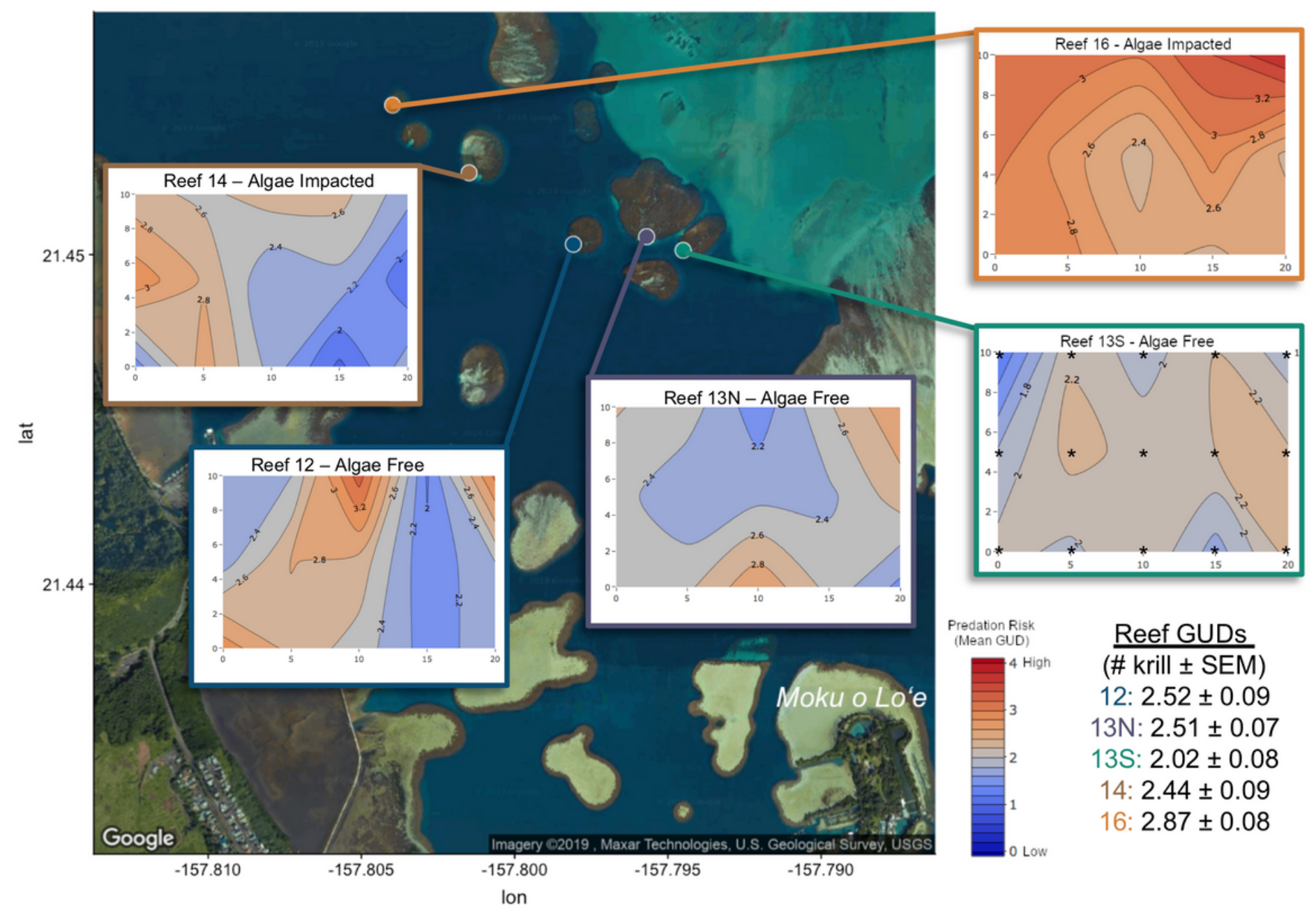

\section{Figure 4}

Reefscape of fear heatmaps based on mean GUDs for 5 experimental reefs within southern Kāne'ohe Bay, O'ahu, Hawai'i. Mean GUD \pm SEM between reefs (bottom right). Warm colors indicate high predation risk and cool colors indicate low predation risk. Krill burrito locations indicated by asterisks on Reef $13 S$ heatmap.

\section{Supplementary Files}

This is a list of supplementary files associated with this preprint. Click to download.

- AppendixS1FinalOecologia.docx 